\title{
Spatial morphology evolution of rural settlements induced by tourism:
}

\section{A comparative study of three villages in Yesanpo tourism area, China}

\author{
XI Jianchao ${ }^{1}$, WANG Xinge ${ }^{1,2}$, KONG Qinqin ${ }^{1,2}$, ZHANG Nan ${ }^{1,2}$ \\ 1. Institute of Geographic Sciences and Natural Resources Research, CAS, Beijing 100101, China; \\ 2. University of Chinese Academy of Sciences, Beijing 100049, China
}

\begin{abstract}
Rural tourism has become an important driving force of rural urbanization in China. As the main reception base and important tourism attraction, tourism village is the core element of the tourism destination system. Integrating the method of PRA (Participatory Rural Assessment), GIS technology and high-resolution remote sensing images, this study aims to analyze the spatial morphology evolution of rural settlements induced by tourism through a comparative study of three tourism villages in Yesanpo tourism area. The results suggest the emergence of a "core-periphery" pattern of the spatial evolution of rural settlements. The closer to the core scenic spot, the higher degree of land-use intensity the village shows, as well as the more mature tourism function and greater change in landscape pattern. In particular, Gougezhuang shows an increase of the floor area ratio from 0.17 to 0.44 , with the most mature tourism function and the lowest authenticity index of 0.448 . Liujiahe has gone through the largest increase in construction land area from 17.3564 ha to 34.1128 ha, with moderately mature tourism function and relatively stable authenticity index of 0.566 . Shangzhuang has the lowest construction land scale and intensity, with the poorest tourism function and most well-preserved landscape authenticity index of 0.942 . Overall, in terms of the spatial morphology, the three villages show the characteristics of "modern town", "semi-urbanization" and "traditional village" respectively, in corresponding to three land development types: "intensive reconstruction type", "enclave extension type" and "in situ utilization type". The spatial evolution patterns of these three villages imply the spatial characteristics of the touristization of traditional villages in different stages, and also have great representative value for the management of rural settlements in tourism areas in China.
\end{abstract}

Keywords: rural settlements; land use; spatial evolution; Yesanpo tourism area

\section{Introduction}

Since the implementation of reform and opening-up policy, China has gone through a rapid

Received: 2013-12-30 Accepted: 2014-03-10

Foundation: National Natural Science Foundation of China, No.40971299

Author: Xi Jianchao (1972-), PhD and Associate Professor, specialized in tourism planning, land use change driven by tourism and the environmental effect. E-mail: xijc@igsnrr.ac.cn 
urbanization and industrialization process (Liu et al., 2010a; Long et al., 2012). This process has resulted in a rapid and far-reaching transition development of rural China, which is often referred to as rural transformation development (RTD). During the RTD process, traditional villages have been reshaped into different directions, which are accompanied with the land-use change, especially the changes of arable and residential land (Liu et al., 2004; Long et al., 2009a; Vos and Meekes, 1999). On the one hand, most of the traditional agriculture-dominated villages are gradually declining and becoming blighted by depopulation and the abandonment of buildings and land, which is called "village-hollowing" in China similar to the "Dying Village" in Europe (Long et al., 2011). On the other hand, with the introduction and development of various industries in rural areas, some new types of villages (industry-dominated rural development type (IDT), rural development type focusing on business, tourism and services industries (BTT), and balanced rural development type (BDT)) are constantly emerging and have become the main forms of rural urbanization in China (Long et al., 2009b). Tourism village in China has become an important new development type in rural China (Long et al., 2009a). Different from other new types of villages, tourism villages are often in remote, backward regions, where tourism is always the principal driving force for local urbanization and RTD. Therefore, interpreting tourism influences on urbanization has important theoretical value to summarize rural urbanization and the processes of RTD in China. However, current studies on land-use change in rural China mainly focus on the agriculture-dominated villages, especially the hollowing villages (Cheng et al., 2001; Feng and Chen, 2003; Lei, 2002; Li and Li, 2008; Long and Li, 2012; Wang et al., 2005; Xu, 2004; Xue, 2001; Xue and $\mathrm{Wu}, 2001$ ), paying little attention to new-type villages, which, to some extent, impedes a better comprehension of the rural urbanization process with Chinese characteristics during the last 30 years. Besides, volumes have been written on the tourism evolutionary models, including the widely popular lifecycle concept (Agarwal, 2001; Bulter, 1980; Papatheodorou, 2004), the core-peripheral structures (Christaller, 1963; Zurick, 1992), the morphology of attractions, destinations, and specialized resorts (Jansen-Verbeke, 1986; Leiper, 1990; Pearce, 1999), and the forms, functions, and expansion of resorts (Middleton, 1982; Pearce, 1978). However, these studies are mainly concerning on evolution process of the tourism area, attention to spatial evolution of rural settlements in the tourism area are scant. Thus, the summary of new urbanization in China and an understanding of tourism destination system's evolution are limited. Based on these considerations, this study takes three tourism villages in Yesanpo tourism area as examples, with the concept of land use and spatial morphology evolution, trying to interpret the following questions: (1) What is the difference on the spatial expansion pattern of rural settlement in different tourism regions? (2) What is the driving force leading to these differences? (3) What is the policy implication behind the rural settlement spatial evolution pattern?

\section{Rural tourism and land-use policy in China}

Tourism has been frequently regarded as an alternative option for rural development and rural regeneration where traditional industries decline, no matter in developed or developing countries (Baležentis et al., 2012; Lee et al., 2013; Panyik et al., 2011; Park et al., 2012; Su, 2011). Rural tourism (RT) has become one of the most important drivers in rural urbaniza- 
tion and RTD in China over the past 30 years (Long et al., 2009b). According to statistics from China National Tourism Administration, rural tourism areas nationwide had received and entertained approximately 720 million tourists as of 2012, creating 216 billion RMB yuan in revenue, with approximately 85,000 villages engaged throughout 31 provinces (autonomous regions and muncipalities) of China (Sun et al., 2011). Rural tourism has significant effects on generating farmers' income and human capital, promoting local employment, optimizing rural economic structure, protecting rural environment, inheriting traditional rural culture, pleasing urban and rural residents and strengthening urban-rural communications (Su et al., 2011).

The tourism village, as a crucial component of rural tourism attraction, dates back to the 1980s of 20th century, first appearing in the suburb of Chengdu (home of the panda) in western China, in the form of "Nongjiale" (Happy Farmer Home) (Su, 2011). With the increasing tourism demand, a series of RT-promoted activities were created by the China National Tourism Administration (CNTA), including "China Rural Tourism Year 1998," "China Eco-tourism Year 1999" and "Chinese Life Tourism Year 2004". In 2007, the CNTA and Ministry of Agriculture of China (CMOA) jointly launched the "Chinese Harmonious Urban and Rural Tours" project and "Rural Tourism Development Program (2009-2015)" aimed at building 1000 demonstrative tourist towns, 10 thousands demonstrative tourism villages, and achieving 771 million tourist visits. As a result, the number of rural communities has greatly increased in pursuit of different forms of RT, particularly "Nongjiale", the local agglomeration of which has fostered the continuous formation of tourism villages. Tourism villages have also developed into various spatial patterns, such as city-attached, scenic region-attached, traffic networks-attached and independent tourism destinations.

Rural tourism actually is the incorporation of agriculture and tourism and it has inevitable relation with rural land (Cheer et al., 2013; Kytzia et al., 2011; Maguigad, 2013). Obviously, the expansion of rural tourism has incurred huge demands in recreational land use and changes in the traditional land-use pattern. Tourism is one of the more dynamic and complex sets of land use. The strong growth in tourism land use has been accompanied by changes in form and distribution and its relationships to other land uses (Nelson, 2001; Nepal, 2007; Wall, 1996; Williams and Shaw, 2009; Xi et al., 2011).

However, two types of land ownerships, namely, state and collective land coexist in the current land administration system in China. Land for rural tourism belongs to collective-owned land which bears the agricultural production, life safeguard and many other functions. Because of the incomplete property rights and policy limitations, in many areas, rural collective-owned land is in a spontaneous, scattered and chaotic state when it is used for rural tourism in the way of land-circulation. In the process, the farmers' revenue is often ignored, their benefits are seriously impaired; some farmers abuse their residential houses to gain greater profits. At the same time, the invisible land circulation market in rural tourism development can lead to the decline of cultivated land, the imbalance of land-use structure, the uncontrolled expansion of urban areas, etc. In a word, the design of land system may hamper rural tourism development. Moreover, for residential land, it is welfare for farmers. Farmers have the right to use their residential land to build new houses for commercial tourism activities, but the old ones must be pulled down, leading to the disappearance of architectural culture. Therefore the competition between welfare-oriented residential and 
profit-oriented commercial land and the contradiction between economic development and environment protection have resulted in severe conflicts among local governments, enterprises, villagers and other stakeholders (Wu et al., 2013), leading to a profound negative impact on the development of tourism villages. Above all, in the medium-term industrialization and urbanization, tourism demand is still increasing year by year. Therefore, how to coordinate rural tourism development and land use via land circulation policy deserves more attention.

\section{Materials and methods}

\subsection{Study area}

The study villages are located in Yesanpo tourism area $\left(115.16^{\circ}-115.30^{\circ} \mathrm{E}, 39.35^{\circ}-39.40^{\circ} \mathrm{N}\right)$, which is a famous tourist resort in northern China, $100 \mathrm{~km}$ away from Beijing, with mountainous and hilly landforms and a total area of $498.5 \mathrm{~km}^{2}$, including 6 independent tourism regions, among which Bailixia canyon is the main attraction (Figure 1). Yesanpo was designated as a five-star (5A) tourism area by CNTA in 2011. It has rich tourism resources, such as steep canyons and beautiful rivers, which is quite popular with Beijing citizens because of the well-preserved eco-environment and proximity. Yesanpo had received 2.24 million tourists and generated 670 million RMB yuan in revenue as of 2011. We choose these three villages as study cases based on the following considerations: (1) They have all played important roles in providing tourism services and all have been designated as national demonstrated sites of rural tourism. (2) They have different locations, with Gougezhuang village 2 $\mathrm{km}$ away from the entrance of Bailixia canyon in the north, Liujiahe village $4 \mathrm{~km}$ in the east

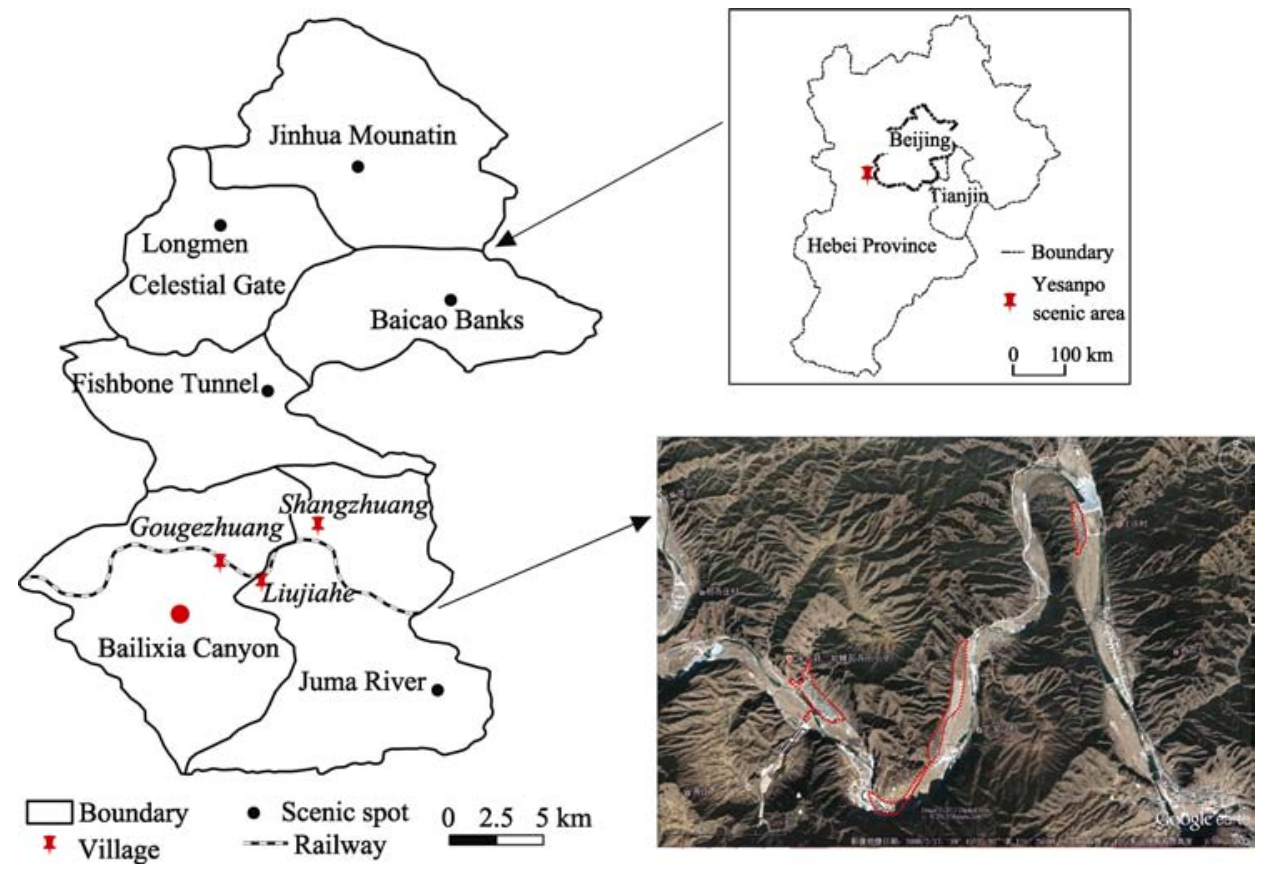

Figure 1 The location of the study villages 
and Shangzhuang village $6 \mathrm{~km}$ in the northeast. (3) The development levels and stages of rural tourism in the three villages are different from each other. Gougezhuang village, with the highest development level, firstly started to engage in rural tourism in 1986; rural tourism in Liujiahe village dates back to 2004, with a moderate level of development; while Shangzhuang village has not involved in tourism until 2007, with the lowest development level currently. In other words, the three villages are representative for all the villages in Yesanpo tourism area with different development stages, thus the study on their spatial evolution processes is supposed to indicate the impacts of rural tourism on land-use pattern in tourism villages. The outline of the three villages is shown in Table 1.

Table 1 The outline of the three villages (2010)

\begin{tabular}{cccccc}
\hline Village & $\begin{array}{c}\text { Household } \\
\text { number }\end{array}$ & $\begin{array}{c}\text { Labor } \\
\text { number }\end{array}$ & $\begin{array}{c}\text { Number of tour- } \\
\text { ism employees }\end{array}$ & $\begin{array}{c}\text { Per capita income } \\
\text { (yuan/person) }\end{array}$ & $\begin{array}{c}\text { Distance to the Bailixia } \\
\text { Canyon scenic area (km) }\end{array}$ \\
\hline Gougezhuang & 542 & 446 & 942 & 6500 & 0.5 \\
Liujiahe & 159 & 177 & 178 & 5500 & 2 \\
Shangzhuang & 202 & 191 & 86 & 4200 & 7.5 \\
\hline
\end{tabular}

\subsection{Data sources}

Based on a survey about the tourism development of Yesanpo in 2010, we did a supplementary investigation between January and April of 2013 to update the information. Both qualitative and quantitative data were collected using primary and secondary data sources. The main tool used to collect primary data was the Participatory Rural Appraisal (PRA) method. Secondary data sources on the land-use evolution of the three villages were also used and it comprised published and unpublished literature on tourism development and land-use change in the Yesanpo tourism area, including policy documents, journal articles, land-use map (1:2000) of 2007 provided by local governments and high-solution remote sensing image from Google earth. The detailed data acquisition process and tourist village land-use classification are available in the reference (Xi et al., 2011).

\subsection{Geographical analysis}

Land use is a dynamic process representing the way and purpose of land use and can be elaborated from three aspects: land-use spatial expansion, land function change and the resultant landscape alteration. Land-use change from 1986 to 2010 was analyzed with ArcGIS9.3, combining the cartographic and census data sources previously described. To elucidate the characteristics of land-use change in various stages, we adopted the following indices.

\subsubsection{Land-use spatial expansion of rural settlement}

In this paper, the speed and intensity of spatial expansion of construction land are quantified from both horizontal and vertical dimensions.

(1) Land-use dynamic index $(K)$ is used to represent the extent to which the construction lands horizontally has expanded during a certain period of time (Sun et al., 2011). It can be calculated as follows: 


$$
K=\frac{U_{b}-U_{a}}{U_{a}} \times \frac{1}{T} \times 100
$$

where $U_{b}$ and $U_{a}$ respectively stand for the area of construction land at the initial and final time points; $T$ is the length of the study period (a).

(2) Floor area ratio $(F)$ is the ratio of buildings' total floor area to the size of the piece of land upon which they are built (Zou, 1994). It can be used to represent the land-use intensity of research area, and it is calculated as follows:

$$
F=R / H
$$

where $R$ refers to the total covered area on all floors of all buildings on a certain plot and $H$ is the area of the plot.

\subsubsection{Land-use function change of rural settlement}

Value of the functional change (IV), represents how important a certain type of land function change is compared with other types in the research area and can be used to reveal the dominant trend of land function change (Zhu et al., 2001). This index can be calculated as follows:

$$
I V=\left(\frac{D_{i}}{D}+\frac{B i}{B}\right) \times 100 \%
$$

where $D_{i}$ is the spot number of a certain kind type; $D$ is the spot number of all kinds of changes; $B_{i}$ is the area of a certain change and $B$ is the total area of all kinds of changes.

\subsubsection{Landscape change of rural settlement}

Landscape change in this paper mainly refers to the villages' spatial morphology change, which can be defined by quoting the definition of authenticity and integrity that are widely applied to cultural heritage studies. Authenticity is a measure of the degree to which the values of a heritage property may be understood to be truthfully, genuinely and credibly. Generally speaking, it mainly includes form and design, materials and substance, use and function, traditions, techniques and management systems, location and setting, language, and so on (Chhabra et al., 2003; Daugstad and Kirchengast, 2013). Integrity is a measure of the wholeness and intactness of the natural or cultural heritage and its attributes. Examining the conditions of integrity requires assessing the extent to which the property: (a) includes all elements necessary to express its outstanding universal value; (b) is of adequate size to ensure the complete representation of the features and processes which convey the property's significance; (c) suffers from adverse effects of development and neglect. Based on this, the index system to evaluate the rural settlement landscape authenticity was built (Table 2) and the Authenticity Index was calculated as follows.

$$
A I=\sum_{i=1} p_{i} f_{i} / \sum_{i=1} p_{i} f_{\max }
$$

where $p$ is the weight of evaluation index, which is attained by analytic hierarchy process (AHP), $\sum p_{i}=1 ; f$ is the estimate of index value; $F_{\max }$ is the maximum of index in theory. 
Table 2 Evaluation index system of rural settlement landscape authenticity

\begin{tabular}{|c|c|c|c|c|}
\hline \multirow{2}{*}{ Subject } & \multirow{2}{*}{ Index } & \multicolumn{3}{|c|}{ Standard } \\
\hline & & (3-5 scores) & (1-3 scores) & (1 score) \\
\hline \multirow{3}{*}{ Building } & History & Built before 1970 & Built during 1970-1980 & Built after 1990 \\
\hline & Typicality & $\begin{array}{l}\text { Buildings with obvious } \\
\text { geographical features }\end{array}$ & $\begin{array}{l}\text { Buildings with relatively } \\
\text { obvious geographical } \\
\text { features }\end{array}$ & $\begin{array}{l}\text { Buildings with poor } \\
\text { geographical features }\end{array}$ \\
\hline & Locality & Traditional building & $\begin{array}{l}\text { Traditional Building with } \\
\text { modern decoration }\end{array}$ & Modern building \\
\hline \multirow{3}{*}{ Yard } & $\begin{array}{l}\text { The gardening } \\
\text { degree of yard }\end{array}$ & Natural plant & $\begin{array}{l}\text { A small amount of mod- } \\
\text { ern decoration }\end{array}$ & Modern decoration \\
\hline & $\begin{array}{l}\text { The living func- } \\
\text { tion of yard }\end{array}$ & Entirely living function & $\begin{array}{l}\text { Half living and tourism } \\
\text { function }\end{array}$ & $\begin{array}{l}\text { Entirely tourism func- } \\
\text { tion }\end{array}$ \\
\hline & $\begin{array}{l}\text { The distance } \\
\text { among yards }\end{array}$ & $\begin{array}{l}\text { Nature configuration } \\
\text { and distance }\end{array}$ & $\begin{array}{l}\text { Regular configuration and } \\
\text { the large distance }\end{array}$ & $\begin{array}{l}\text { Regular configuration } \\
\text { and equidistant, small } \\
\text { distance }\end{array}$ \\
\hline \multirow{3}{*}{ Settlement } & $\begin{array}{l}\text { The variety of } \\
\text { rural public } \\
\text { space }\end{array}$ & $\begin{array}{l}\text { With traditional public } \\
\text { space at the center }\end{array}$ & $\begin{array}{l}\text { With traditional public } \\
\text { space away from the } \\
\text { center }\end{array}$ & $\begin{array}{l}\text { With other space at the } \\
\text { center }\end{array}$ \\
\hline & $\begin{array}{l}\text { The convenience } \\
\text { of internal vil- } \\
\text { lage traffic }\end{array}$ & $\begin{array}{l}\text { Natural materials, with } \\
\text { low accessibility }\end{array}$ & $\begin{array}{l}\text { Semi-natural materials, } \\
\text { with certain accessibility }\end{array}$ & $\begin{array}{l}\text { Human materials, with } \\
\text { high accessibility }\end{array}$ \\
\hline & $\begin{array}{l}\text { The integrity of } \\
\text { settlement }\end{array}$ & $\begin{array}{l}\text { With more than } 75 \% \\
\text { perfectly reserved } \\
\text { historic appearance }\end{array}$ & $\begin{array}{l}\text { With } 25 \%-75 \% \text { perfectly } \\
\text { reserved historic appear- } \\
\text { ance }\end{array}$ & $\begin{array}{l}\text { With less than } 25 \% \\
\text { perfectly reserved his- } \\
\text { toric appearance }\end{array}$ \\
\hline
\end{tabular}

\section{Results}

\subsection{The spatial expansion of three villages}

Table 3 indicates the intensity and speed of the horizontal expansion of the three villages. From 1986 to 2010, the construction land of Liujiahe village expanded at the fastest rate, with an annual increase of $6981.8 \mathrm{~m}^{2}$, followed by Gougezhuang village $\left(3012.0 \mathrm{~m}^{2} / \mathrm{a}\right)$ and then Shangzhuang village $\left(1237.6 \mathrm{~m}^{2} / \mathrm{a}\right)$.

Table 3 Construction expansion of three villages during the period of study

\begin{tabular}{cccccc}
\hline Village & $\begin{array}{c}\text { Construction area of } \\
\text { initial phase }\left(\mathrm{m}^{2}\right)\end{array}$ & $\begin{array}{c}\text { Construction area of } \\
\text { current phase }\left(\mathrm{m}^{2}\right)\end{array}$ & $\begin{array}{c}\text { Expansion } \\
\text { area }\left(\mathrm{m}^{2}\right)\end{array}$ & $\begin{array}{c}\text { Expansion } \\
\text { speed }\left(\mathrm{m}^{2} / \mathrm{a}\right)\end{array}$ & $K(\% / \mathrm{a})$ \\
\hline Gougezhuang & 87794 & 160082 & 72288 & 3012.0 & 3.40 \\
Liujiahe & 173564 & 341128 & 167564 & 6981.8 & 4.00 \\
Shangzhuang & 49727 & 79430 & 29703 & 1237.6 & 2.50 \\
\hline
\end{tabular}

Figure 2 presents the spatial pattern of land expansion of the three villages. Specifically, Gougezhuang village and Shangzhuang village followed the "core-periphery" pattern, showing the characteristics of linear expansion. Whereas, Liujiahe village has experienced a spatially discontinuous expansion, with some new buildings occurred in the southwest of the village next to the scenic cableway of Bailixia canyon and the eastern part of the village ad- 
jacent to the Juma River. The increase of construction land in Shangzhuang village was limited to a slight expansion in the northern and southern parts of the village.

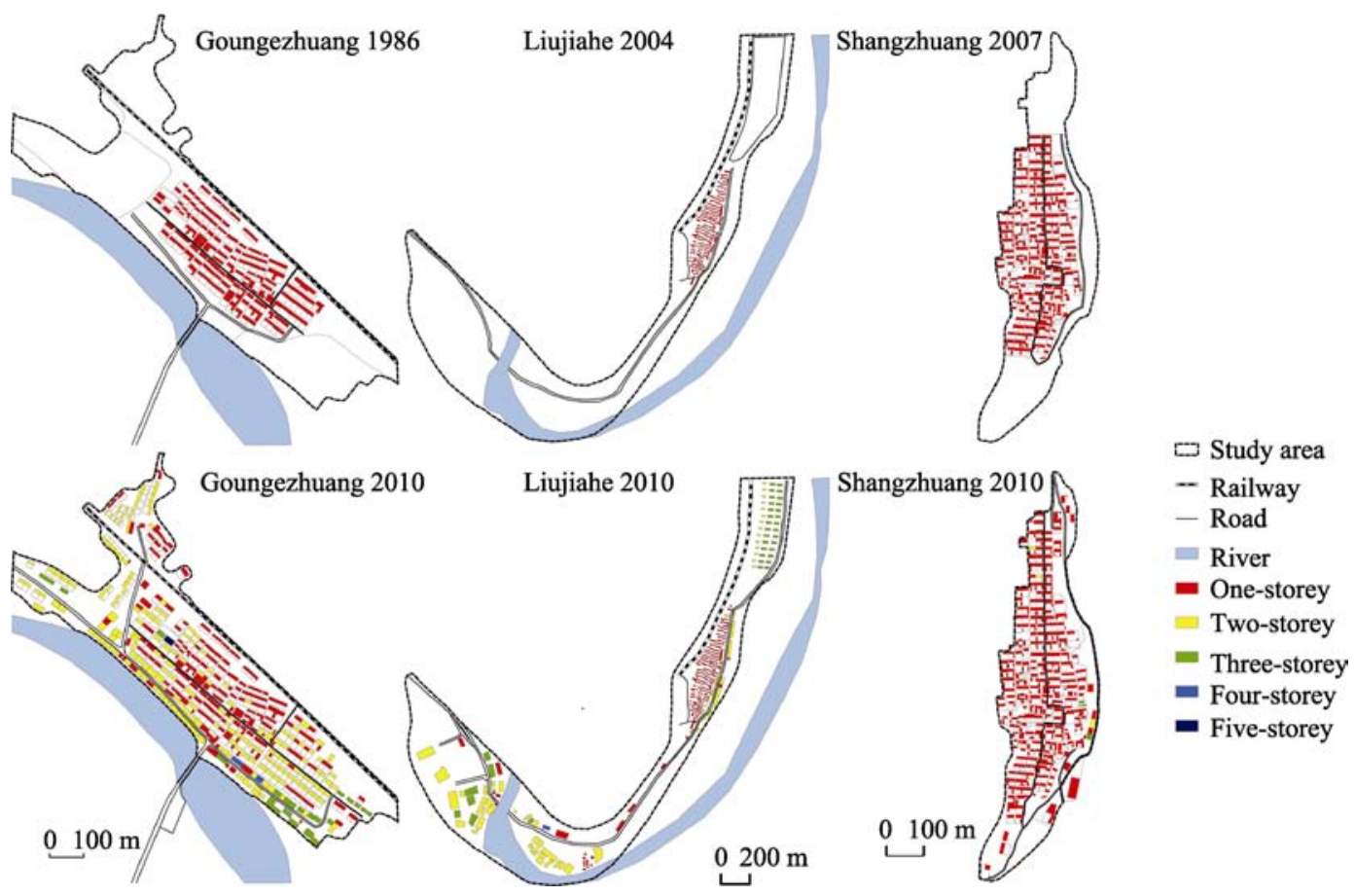

Figure 2 Spatial-temporal changes of land-use expansion of the three villages during the study period

As shown in Table 4, land use-intensity of the three villages had changed to different degrees from 1986 to 2010. The floor area ratio of Liujiahe village and Gougezhuang village increased to a large extent, whereas that of Shangzhuang village decreased slightly. In other words, the construction land of Shangzhuang village mainly expanded in horizontal dimension, while Liujiahe village and Gougezhuang village expanded in both horizontal and vertical dimensions.

Table 4 Changes of the villages' plot ratio during the study period

\begin{tabular}{cccc}
\hline The plot ratio & Gougezhuang (1986-2010) & Liujiahe (2004-2010) & Shangzhuang (2007-2010) \\
\hline The initial phase & 0.17 & 0.08 & 0.28 \\
The current phase & 0.44 & 0.34 & 0.26 \\
The changes & 0.27 & 0.26 & -0.02 \\
\hline
\end{tabular}

\subsection{Changes in land-use function}

As shown in Figure 3 and Table 5, the expansion of construction land was accompanied by tourism. The land functions of the three villages were changed from meeting villagers' living needs satisfying tourists' demand, it can be reflected in the construction of accommodations, shopping, caterings and entertainments. Compared with Shangzhuang village, Gougezhuang village and Liujiahe village have experienced a relatively drastic alteration of land function. 


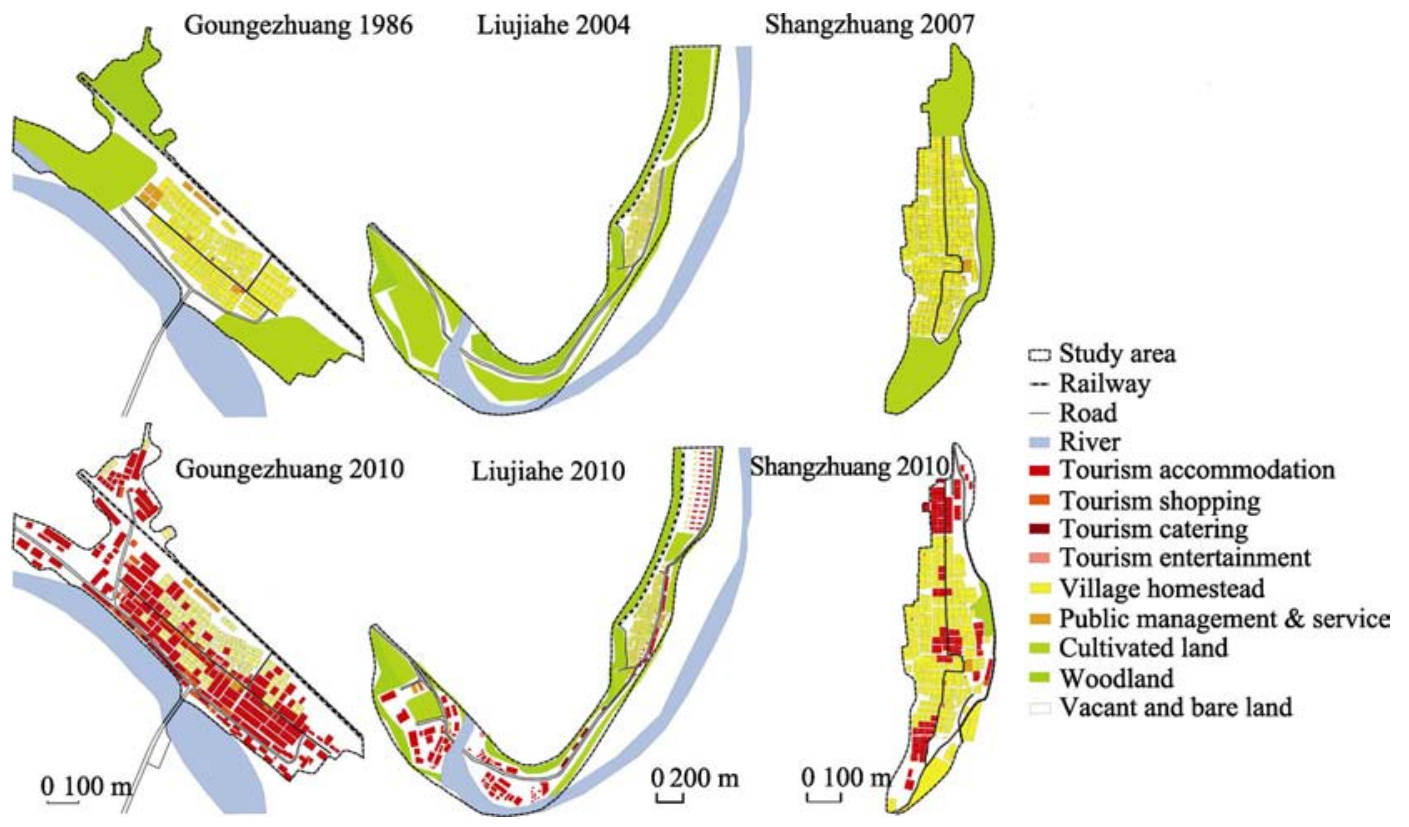

Figure 3 Land-use function changes of the three villages during the study period

Table 5 Dominant types of land-use change in different villages during the study period

\begin{tabular}{|c|c|c|c|c|}
\hline \multirow{2}{*}{ Original land use type } & \multirow{2}{*}{ Conversion of land-use type } & \multicolumn{3}{|c|}{ IV } \\
\hline & & Gougezhuang & Liujiahe & Shangzhuang \\
\hline \multirow[t]{3}{*}{ Public service land } & Tourist accommodation & 4.607 & 0.000 & 3.334 \\
\hline & Ordinary residential land & 0.000 & 0.000 & 3.198 \\
\hline & Other land & 0.000 & 0.000 & 21.202 \\
\hline \multirow[t]{4}{*}{$\begin{array}{l}\text { Ordinary residential } \\
\text { land }\end{array}$} & Tourist accommodation & 821.881 & 1.236 & 26.313 \\
\hline & Tourist shopping & 65.781 & 0.000 & 5.289 \\
\hline & Tourist entertainment & 167.390 & 0.000 & 0.000 \\
\hline & Other land & 0.000 & 17.623 & 0.000 \\
\hline \multirow[t]{6}{*}{ Cultivated land } & Public service land & 0.000 & 1.645 & 9.388 \\
\hline & Other land & 677.165 & 677.165 & 59.106 \\
\hline & Ordinary residential land & 0.000 & 4.333 & 19.551 \\
\hline & Tourist accommodation & 25.560 & 28.785 & 34.982 \\
\hline & Tourist shopping & 2.940 & 1.064 & 1.240 \\
\hline & Tourist entertainment & 1.350 & 1.350 & 0.000 \\
\hline \multirow{6}{*}{$\begin{array}{l}\text { Other land } \\
\text { vacant and bare land }\end{array}$} & Ordinary residential land & 10.976 & 18.598 & 11.490 \\
\hline & Tourist accommodation & 0.867 & 18.989 & 4.907 \\
\hline & Tourist shopping & 233.617 & 0.987 & 0.000 \\
\hline & Tourist catering & 100.824 & 0.987 & 0.000 \\
\hline & Tourist entertainment & 1.524 & 0.611 & 0.000 \\
\hline & Public service land & 0.000 & 1.621 & 0.000 \\
\hline
\end{tabular}


The transition process of land function in Gougezhuang village was most complicated, with forestry land transformed to tourism accommodation land, residential land transformed to tourism accommodation and entertainment land and other land transformed to tourism shopping and catering land. For Liujiahe village, the conversion from traditional residential land and other land to tourism accommodation land was the dominant transition type. The conversion of land function change in Shangzhuang village was relatively simple, with traditional residential land and cultivated land transformed to tourism accommodation land.

Figure 3 and Table 4 also present the spatial pattern of land-use change in the three villages. For Gougezhuang village, traditional residential land shrank into a small region in the northwest of the village, away from the main street. Tourism shopping, catering and entertainment land transformed from residential land were scattered along the Juma River and the main street of the village. While, tourism accommodation land agglomerated in the northwest and southeast of the village. For Liujiahe village, the spatial pattern of land-use change also showed the characteristics of discontinuity: the majority of traditional residential land was preserved; a small amount of tourism accommodations and shops were located along the main street of the village, and a lot of tourism accommodations agglomerated at the upstream of the Juma River next to the cableway of Bailixia canyon. In Shangzhuang village, tourism accommodations were scattered along the main street.

\subsection{The authenticity of the villages landscape}

As shown in Table 6 and Figure 4, the landscape of the three villages had experienced great changes from 1986 to 2010. For Gougezhuang village, rural landscape was seriously damaged; most of the traditional residences with yard were transformed to modern multi-storey buildings. For Liujiahe village, the traditional residences in the central part of the village were well preserved. In the southwest next to the cableway, there are some new buildings with disordered distribution. While, in the northeast, new buildings were arranged in an ordered way similar to that in urban areas. For Shangzhuang village, traditional rural landscape was preserved very well, most buildings are still one-story, built by stones with natural distribution pattern.

Table 6 Total scores of the authenticity of the three villages

\begin{tabular}{|c|c|c|c|c|}
\hline \multirow{2}{*}{ Mandatory layer } & \multirow{2}{*}{ Index } & \multicolumn{3}{|c|}{ Village score } \\
\hline & & Gougezhuang & Liujiahe & Shangzhuang \\
\hline \multirow{3}{*}{ Building style } & History & 0.277 & 2.254 & 4.896 \\
\hline & Typicality & 0.254 & 2.569 & 4.653 \\
\hline & Locality & 0.251 & 2.988 & 4.264 \\
\hline \multirow{3}{*}{ Yard structure } & The gardening degree of yard & 0.364 & 2.421 & 4.699 \\
\hline & The living function of yard & 0.132 & 3.237 & 4.635 \\
\hline & The special distance between households & 0.222 & 2.452 & 4.633 \\
\hline \multirow{3}{*}{$\begin{array}{l}\text { Settlement } \\
\text { pattern }\end{array}$} & The variety of rural public space & 0.225 & 2.136 & 4.256 \\
\hline & The convenience of internal village traffic & 0.336 & 2.251 & 4.231 \\
\hline & The integrity of settlements & 0.256 & 2.241 & 4.987 \\
\hline$A I$ & & 0.048 & 0.566 & 0.942 \\
\hline
\end{tabular}




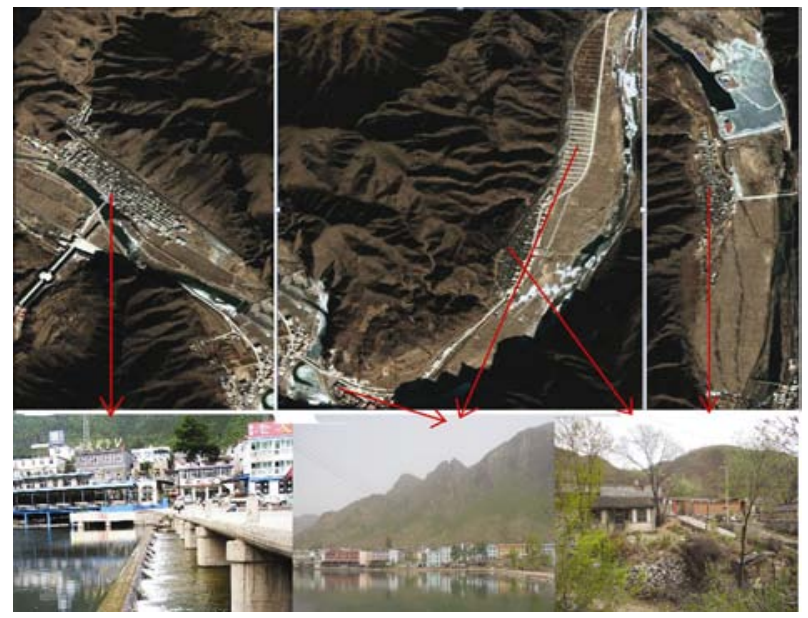

Figure 4 The remote sensing image in 2008 and villages landscape style schematic of Gougezhuang village (left), Liujiahe village (middle), and Shangzhuang village (right) in 2010

\section{Conclusions and discussion}

\subsection{Conclusions}

As the main reception base and important tourism attraction, tourism village is the core element of the tourism destination system. Integrating the method of PRA (Participatory Rural Assessment), GIS technology and high-resolution remote sensing images, this study tries to analyze the spatial evolution of rural settlements induced by tourism through a comparative study of three tourism villages in Yesanpo tourism area. The results suggest the emergence of a "core-periphery" pattern of the spatial evolution of rural settlements with different locations. The closer to the core scenic spot, the higher degree of land-use intensity a village shows, as well as the more mature tourism function and greater change in landscape pattern. In particular, Gougezhuang village shows an increase of the floor area ratio from 0.17 to 0.44 , with the most mature tourism function and destroyed landscape authenticity as well and it has the lowest authenticity index of 0.448 . Liujiahe village has gone through a largest increase of $96.54 \%$ in construction land area, with moderately mature tourism function and relatively stable authenticity of 0.566 . Shangzhuang village, in contrast, has the lowest construction land scale and intensity, with the poorest tourism function and most well-preserved landscape authenticity of 0.942. Overall, in terms of the spatial morphology, Gougezhuang, Liujiahe and Shangzhuang have shown the characteristics of "modern town", "semi-urbanization" and "traditional village" respectively, in corresponding to three land development types: "intensive reconstruction type", "enclave extension type" and "in situ using type". The spatial evolution patterns of the three villages are of great representative value for the management of rural settlements in tourism areas.

\subsection{Discussion}

Recently, rural tourism has become an important driving force for rural urbanization in China, especially in the remote and backward regions. Xi et al. (2011) investigated the 


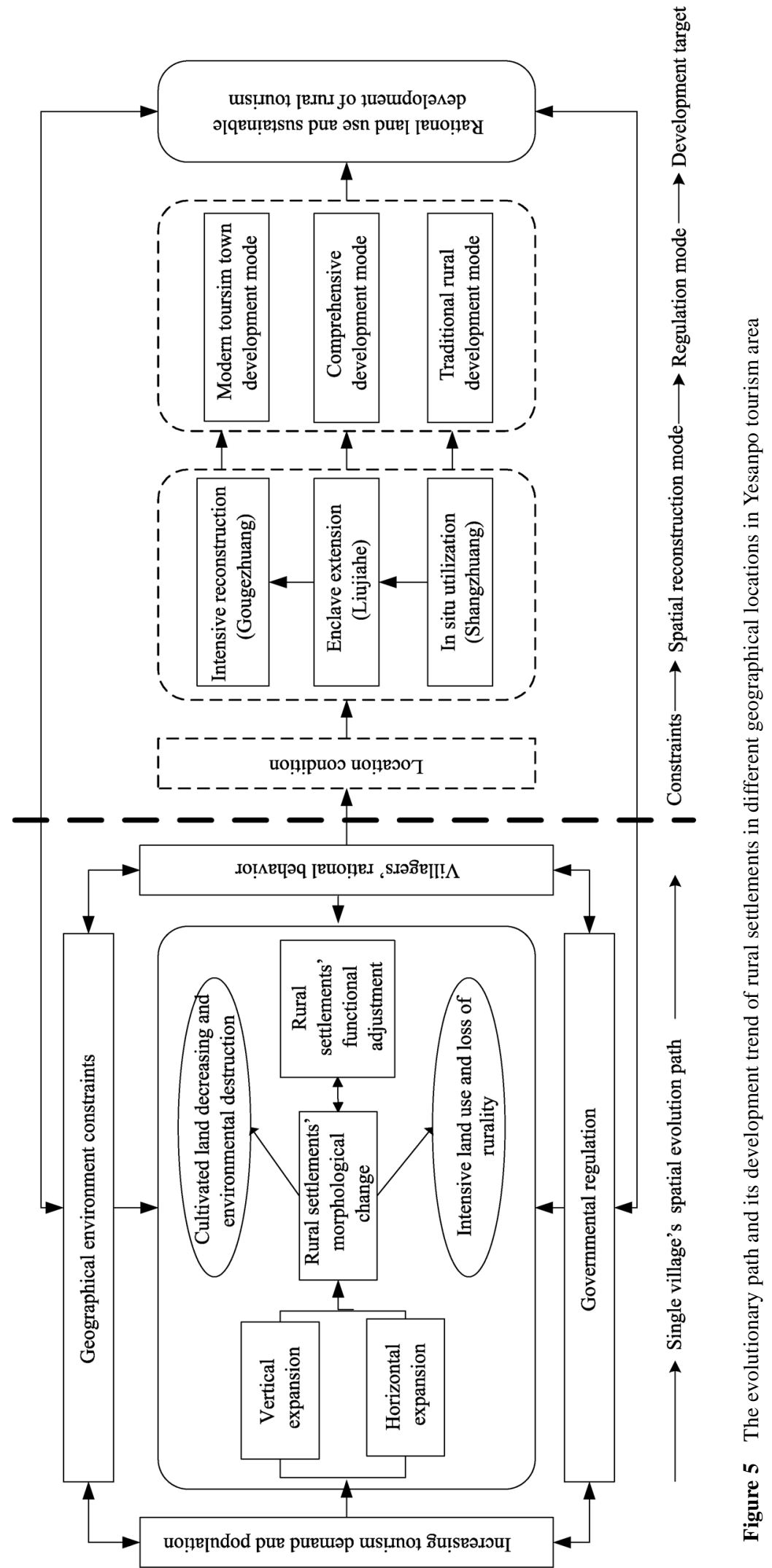


transformation process of a single village to modern tourism town, under the interaction among natural geographical environment, tourism demand, villagers' rational behavior and governmental regulation. Whereas the different spatial evolution patterns of the three villages with different locations actually imply the spatial feature of the villages' touristization process in different stages, among which the final stage is characterized by the modern tourism town. Furthermore, the self-organized evolution of rural settlements in Yesanpo has exhibited a "core-periphery" pattern, which is consistent with the findings (2007) in the Annapurna region of Nepal. This spatial differentiation also indicates that location is the core factor determining not only the evolution stage of rural settlements, but also the evolution path (Figure 5).

Rurality is the unique selling point of rural tourism and an important prerequisite for sustainable development of rural tourism (Lane, 1994). Contrary to the hollowing trend of traditional villages resulted from land abandonment and depopulation, substantial population inflow dominated by tourists in tourism villages has raised demands for adequate reception capacity and consequently led to the increase of land-use intensity, which, to some extent, has given rise to the loss of rurality. As for the three villages analyzed in this paper, Gougezhuang village goes furthest in the urbanization process, with the highest land-use intensity and the largest reception capacity. The loss of rurality, however, is also most serious there. Liujiahe has well preserved the traditional settlements and also satisfied the demands on reception capacity through the construction of new settlements. In comparison, the traditional rural landscape is best preserved in Shangzhuang village, where the reception capacity and development level however, are quite limited. Apparently, there exist great conflicts between the protection of rurality and expansion of reception capacity, the balance between which should be achieved in order for the sustainable development of rural tourism.

In addition, different land-use policies and management measures are also required for tourism villages within different evolution stages. For villages like Gougezhuang, the agglomeration of tourism industry through tourism function zoning is emphasized to satisfy the market demands better. For villages like Liujiahe, the coordination between tourism development and protecting rurality is highlighted. Whereas the protective development mode is appropriate for villages like Shangzhuang. These various development modes should be specifically implemented from the dimensions of rural governance, institutional improvement and cultural reconstruction

\section{References}

Agarwal S, 2001. Restructuring seaside tourism: The resort lifecyle. Annals of Tourism Research, 29(1): 25-55.

Baležentis T, Kriščiukaitienė I, Baležentis A et al., 2012. Rural tourism development in Lithuania (2003-2010): A quantitative analysis. Tourism Management Perspectives, 2(3): 1-6.

Bulter R, 1980. The concept of a tourism area cycle of evolution: Implications for management of resources. Canadian Geographer, 24(1): 5-12.

Cheer J M, Reeves K J, Laing J H, 2013. Tourism and traditional culture: Land diving in Vanuatu. Annals of Tourism Research, 43: 435-455.

Cheng L S, Feng W Y, Jiang L H, 2001. The analysis of rural settlement hollowizing system of the southeast of Taiyuan Basin. Acta Geographica Sinica, 56(4): 437-446. (in Chinese)

Chhabra D, Healy R, Sills E, 2003. Staged authenticity and heritage tourism. Annals of Tourism Research, 30(3): 
702-719.

Christaller W, 1963. Some considerations of tourism location in Europe: The peripheral regions-underdeveloped countries-recreation areas. Regional Science Association Papers, 12(1): 513-527.

Daugstad K, Kirchengast C, 2013. Authenticity and the pseudo-backstage of agri-tourism. Annals of Tourism Research, 43: 170-191.

Feng W Y, Chen X M, 2003. Analysis on the rural settlement expansion of the Jinzhong Plain. Human Geography, 18(6): 93-96. (in Chinese)

Jansen-Verbeke M, 1986. Inner-city tourism: Resources, tourists and promoters. Annals of Tourism Research, 13(1): 79-100.

Kytzia S, Walz A, Wegmann M, 2011. How can tourism use land more efficiently? A model-based approach to land-use efficiency for tourist destinations. Tourism Management, 32(3): 629-640.

Lane B, 1994. What is rural tourism? Journal of Sustainable Tourism, 2(1/2): 7-21.

Lee S H, Choi J Y, Yoo S H et al., 2013. Evaluating spatial centrality for integrated tourism management in rural areas using GIS and network analysis. Tourism Management, 34: 14-24.

Lei Z D, 2002. Rural habitat empty-disusing concept and quantitative analysis modes. Journal of Northwest University (Natural Science Edition), 32(4): 421-424. (in Chinese)

Leiper N, 1990. Tourist attraction systems. Annals of Tourism Research, 17(3): 367-384.

Li J, Li X J, 2008. The microscopic analysis on village-hollowing in medium income and hilly land region of Henan Province. China Population, Resources and Environment, 18(1): 170-175. (in Chinese)

Liu J Y, Zhang Z X, Xu X L, 2010. Spatial patterns and driving forces of land use change in China during the early 21st century. Journal of Geographical Sciences, 20(4): 483-494.

Liu S H, Chen T, Cai J M, 2004. Peri-urbanization in China and its major research issues. Acta Geographica Sinica, 59(Suppl.): 101-108. (in Chinese)

Long H L, Li T T, 2012. The coupling characteristics and mechanism of farmland and rural housing land transition in China. Journal of Geographical Sciences, 22(3): 548-562.

Long H L, Li Y R, Liu Y S et al., 2012. Accelerated restructuring in rural China fueled by 'increasing vs. decreasing balance' land-use policy for dealing with hollowed villages. Land Use Policy, 29(1): 11-22.

Long H L, Liu Y S, Zou J, 2009a. Assessment of rural development types and their rurality in eastern coastal China. Acta Geographica Sinica, 64(4): 426-434. (in Chinese)

Long H L, Zou J, Liu Y S, 2009b. Differentiation of rural development driven by industrialization and urbanization in eastern coastal China. Habitat International, 33(4): 454-462.

Long H L, Zou J, Pykett J et al., 2011. Analysis of rural transformation development in China since the turn of the new millennium. Applied Geography, 31(3): 1094-1105.

Maguigad V M, 2013. Tourism planning in archipelagic Philippines: A case review. Tourism Management Perspectives, 7: 25-33.

Middleton V T C, 1982. Tourism in rural areas. Tourism Management, 3(1): 52-58.

Nelson P B, 2001. Rural restructuring in the American West: land use, family and class discourses. Journal of Rural Studies, 17(4): 395-407.

Nepal S K, 2007. Tourism and rural settlements Nepal's Annapurna region. Annals of Tourism Research, 34(4): 855-875.

Panyik E, Costa C, Rátz T, 2011. Implementing integrated rural tourism: An event-based approach. Tourism Management, 32(6): 1352-1363.

Papatheodorou A, 2004. Exploring the evolution of tourism resorts. Annals of Tourism Research, 31(1): $219-237$.

Park D B, Lee K W, Choi H S et al., 2012. Factors influencing social capital in rural tourism communities in South Korea. Tourism Management, 33(6): 1511-1520.

Pearce D G, 1978. Form and function in French resorts. Annals of Tourism Research, 5(1): 142-156.

Pearce D G, 1999. Tourism in Paris studies at the microscale. Annals of Tourism Research, 26(1): 77-97. 
Su B, 2011. Rural tourism in China. Tourism Management, 32(6): 1438-1441.

Su S, Jiang Z, Zhang Q et al., 2011. Transformation of agricultural landscapes under rapid urbanization: A threat to sustainability in Hang-Jia-Hu region, China. Applied Geography, 31(2): 439-449.

Sun Y, Liu Z Q, Wang Q B et al., 2011. Spatial expansion of urban land use and its driving forces in Shenyang city over the past century. Resources Science, 33(11): 2022-2029. (in Chinese)

Vos W, Meekes H, 1999. Trends in European cultural landscape development: Perspectives for a sustainable future. Landscape and Urban Planning, 46(1-3): 3-14.

Wall G, 1996. Perspectives on tourism in selected Balinese villages. Annals of Tourism Research, 23(1): $123-137$.

Wang C X, Yao S M, Chen C H, 2005. Empirical study on “village-hollowing” in China. Scientia Geographica Sinica, 25(3): 257-262.

Williams A M, Shaw G, 2009. Future play: Tourism, recreation and land use. Land Use Policy, 26(1): 326-335.

Wu G C, Niu X, Xu H Z, 2013. Study on land transfer risk evaluation during the development of rural tourism. Economic Geography, 33(3): 187-191. (in Chinese)

Xi J C, Zhao M F, Ge Q S, 2011. The micro-scale analysis of rural settlement land-use pattern: A case study of Gougezhuang village of Yesanpo scenic area in Hebei Province. Acta Geographica Sinica, 66(12): 1707-1717. (in Chinese)

$\mathrm{Xu} \mathrm{S} \mathrm{H,} \mathrm{2004.} \mathrm{The} \mathrm{integral} \mathrm{regimes} \mathrm{and} \mathrm{countermeasure} \mathrm{study} \mathrm{on} \mathrm{hollow-oriented} \mathrm{houses} \mathrm{in} \mathrm{rural} \mathrm{regions.} \mathrm{Terri-}$ tory \& Natural Resources Study, (1): 11-12. (in Chinese)

Xue L, 2001. Study on the inner decaying village and the countermeasures with Jiangsu Province as the case. City Planning Review, 25(6): 8-13. (in Chinese)

Xue L, Wu M, 2001. A discussion about the heteromorphism of the rural settlements and its policy in Jiangsu Province. Urban Planning Forum, (1): 41-45. (in Chinese)

Zhu H Y, Li X B, He S J et al., 2001. Spatio-temporal change of land use in Bohai Rim. Acta Geographica Sinica, 56(3): 253-260. (in Chinese)

Zou D C, 1994. Floor area ratio. Urban Planning, (1): 19-23. (in Chinese)

Zurick D N, 1992. Adventure travel and sustainable tourism in the peripheral economy of Nepal. Annals of the Association of American Geographers, 82(4): 604-628. 